\title{
Exemption and Exclusion from French Second Language Programs in Canada: Consideration of Novice Teachers' Rationales
}

\author{
Katy Arnett \\ St. Mary's College of Maryland \\ Callie Mady \\ Nipissing University
}

\begin{abstract}
This case study is focused on a small group of novice teachers of French as a second language (FSL) in the Canadian K-12 context. More specifically, it presents the perceptions and ideas that inform new teachers' views toward the suitability of French as a second language and toward exemption and/or exclusion for two populations: students who are English language learners (ELLs) and students with learning difficulties and other special needs. The data from the current study are drawn from semi-structured interviews implemented over the first four years of a larger five-year study. The findings reveal that there was general openness to the idea of including students who are ELLs and who have learning difficulties in FSL programs. However, in some instances the participants viewed exemption as a reasonable path for the student population when, in isolated ways, the program was considered as unsuitable for their needs.
\end{abstract}

Canadian policy documents over the last few decades, specifically those linked to French as a second language (FSL) programming, and French Immersion (FI) ${ }^{1}$ in particular, have intimated or directly stated that certain students were better candidates for FSL learning opportunities than others (e.g., Peel District School Board, n.d.). In such a context, some students were not included in FSL programming (i.e., compulsory FSL studies and/or optional FI programs). The work of Arnett (2013) has revealed that the practice of such

\footnotetext{
${ }^{1}$ In FI programs, subject study is delivered in French for a minimum of $50 \%$ of instructional time; students learn the language through their study of the content areas.
} 
exemptions in Canada began in the 1970s, around the time the construct of learning disabilities $^{2}$ was being developed politically and pedagogically. As FI launched in 1965 in Québec and school systems over the next decade worked quickly to add the program option to the curricula in their school districts, there appeared to be great interest in establishing the benefits and virtue of the program as part of the persuasion process (i.e., using positive aspects to encourage program uptake). Arnett (2013) found that in some situations in those first programs, school systems appear to have purposefully selected students with strong academic profiles on the belief that they were the best candidates for showing how well the program worked and thus for facilitating more support. This happened in spite of evidence from the original study (Lambert \& Tucker, 1972) that students with a range of academic profiles, including students with profound intellectual needs, were able to develop academic skills through FI.

In the mid-1970s, a pair of studies (Trites \& Price, 1976, 1977) emerged from Ottawa that promoted the idea that students with language-based learning disabilities were not good candidates for FI. While the methodology was quickly challenged, and other studies revealed that students with language-based learning difficulties were becoming proficient in French (e.g., Bruck 1978, 1982), FI programs then became linked to the premise that they were only for students who were academically strong. While students with learning disabilities were not exempt from the program, being that it was an optional path for FSL studies, it was certainly the case that students with certain learning needs were excluded from the FI program. However, Arnett's 2013 study deduced through interviews with individuals who were teaching FSL in the 1970s and 1980s that the practice of exempting students with learning disabilities and other special needs from required FSL program study-particularly for the core French ${ }^{3}$ option in many provinces - emerged in this time period. Further, Mady and Black (2012) confirmed that through the first decade of the new millennium, it was not uncommon to find either anecdotal or actual policy evidence of students with learning difficulties being exempted from FSL study in several provinces in Canada. These practices - whether codified or ad hoc-were premised on the belief that FSL study was suited only for certain students, contributing to a perception that FSL study has been for academically elite students.

In addition to students with learning difficulties, English language learners (ELLs) have been exempt from FSL learning opportunities, whether core French or FI. Mady (2007) revealed exclusionary practices by principals and guidance counsellors who recommended ELLs be exempt from obligatory core French classes for a variety of reasons ranging from: (a) FSL being an unnecessary burden for ELLs, to (b) students' advanced age (i.e., ELLs were adolescents at time of arrival to Canada), to (c) the need for ELLs to focus on English. Through interviews with ELL parents, Mady (2012b) discovered that ELLs were often discouraged from if not refused FI programming. This

\footnotetext{
${ }^{2}$ Learning disabilities refer to difficulties identified through psycho-educational assessment. We use the term adopted by Canadian Ministries of Education while we recognize that learning disabilities can often be addressed with strategy use unlike other forms of disabilities.

${ }^{3}$ In core French programs, French is taught as a subject for one 25- to 75-minute period each day or several periods each week, depending on the level (elementary or secondary). In FI programs, subject study is delivered in French for a minimum of 50\% of instructional time; students learn the language through their study of the content areas.
} 
practice of excluding ELLs from immersion was also confirmed by ELL high school graduates (Mady, 2012a).

Similar to the exemption of students with learning difficulties, exclusion of ELLs from FSL programming contradicts research highlighting their desire and ability to succeed. Multiple studies (e.g., Dagenais \& Berron, 2001; Dagenais \& Jaquet, 2000; Dagenais \& Moore, 2008) from British Columbia with ELL parents of children in FI underscored the parental desire for their children to add English and French to their children's language repertoires. Mady (2010) also revealed ELLs' motivation to study FSL. Indeed, such enthusiasm extends to the immigrant population in Canada in general as revealed by federal research (Parkin \& Turcotte, 2003). Further to their willingness to learn both of Canada's official languages, studies have shown ELLs' ability to perform on par with, or at times outperform, their Canadian-born peers in both the core French (Mady, 2013a) and the FI context (Mady, 2015a).

\section{Rationale for Exemptions}

Policy. Policies, or lack thereof, can be influential in the application of exemptions from FSL study for students with learning difficulties and ELLs. British Columbia, for example, has an explicit policy that allows these two groups of students to be exempt from their obligatory second language requirement (Province of British Columbia, 2004). In addition to explicit policies, lack of policies may also encourage the application of exemptions from FSL for these two groups of students. In their review of provincial and territorial polices on inclusion in FSL, Mady and Black (2012) discovered that only 5 of 132 policies they examined provided opportunities leading to equitable inclusion in FSL programs in Canada. Delaney (2002) suggested that this lack of policies can create a context in which ad hoc practices become legitimized. It is perhaps due to a lack of formal policies that the exclusionary practices cited above have developed.

Gatekeepers. Lack of policies allows for a variety of decisions to be made by a variety of educational stakeholders. As found in Bourgoin (2016), at least as it pertains to the context of FI programs in eastern Canada, classroom teachers in the years preceding the start of FI instruction exhibited considerable gatekeeping power over access to the program. As revealed through the interviews in her study, the teachers based their recommendations on perceptions of the students' academic progress and achievement: Students who were doing well in school so far were considered to be better suited for FI (Bourgoin, 2016). Further, in this same study, the teachers recommended students for FI who were perceived as being in need of additional challenge or enrichment, while not recommending students who were viewed as being in need of additional support to develop academically. As Bourgoin contended, the teachers' recommendations for FI were based on personal conceptions about the program, rather than on research, which has yet to confirm that certain students cannot find success in the FI program (e.g., Genesee, 2007, 2008, 2012).

The Bourgoin (2016) study revealed that the decision about who can or should study a second or foreign language often rests in the hands of individuals who may hold an uninformed perspective. Such individuals may not have a current understanding of the research about the intersection of learner needs and language teaching pedagogy; may 
hold personal beliefs about the value of second or foreign language education for certain types of learners; and/or may otherwise hold the view that students should be exempted or excluded based on their individual challenges, rather than the view that instructors are responsible for responding to students' needs in the classroom. Likewise, FSL exemptions from a variety of stakeholders have been applied to the ELL community. In addition to the principals and guidance counsellors mentioned above, kindergarten teachers in Mady's (2016) study revealed applying additional criteria when considering whether to recommend ELLs for of FI. In response to a questionnaire, the majority of kindergarten teachers from the English mainstream program, in which FI begins in Grade 1, indicated that ELLs should focus on English acquisition and denied the possibility for cross-linguistic support.

\section{Recent Policy and Research Trends}

In recognition of the exclusionary practices above, in more recent years there have been efforts to reverse course and promote all FSL program options as available to all students, regardless of a range of needs (e.g., Alberta Education, 2013; Ontario Ministry of Education, 2015). Such a change in direction is supported by research that has revealed the potential for these two groups of students in particular to succeed in FI and core French programs: ELLs (e.g., Mady, 2013b, 2015a; 2015b) and students with learning challenges or special education needs (e.g., Arnett, 2013; Le Bouthillier, 2013). Support for the inclusion of these groups has been highlighted in previous studies of teacher practices in core French (Arnett 2003, 2010) and FI (Bourgoin, 2014), in which standard pedagogical moves within these settings were found to often align with recommended adaptive teaching practices for students with language-based learning difficulties and for additional language learners. Collectively, these research findings corroborate the logic behind some of this policy shifting.

Given the previous findings of Bourgoin (2014) and Mady (2013b, 2015b), and in light of the fact that policies have been shifting across Canada, it is worthwhile to consider how newly prepared teachers, recently inducted to the profession, challenge and conform to past practices and newer paradigms. The current case study is focused on a small group of novice teachers in the Canadian K-12 context. Our study examines the perceptions and ideas that inform new teachers' views regarding exemption and/or exclusion of the two aforementioned populations in the FSL classroom: students who are ELLs and students with learning difficulties and other special needs.

Thus, the goal of the present paper is to address the following questions:

1. What do novice FSL teachers believe, over time, about exemptions from FSL program options and about program suitability for ELLs and students with learning difficulties?

2. To what extent are these beliefs dynamic, considering the novice teachers' progression from teacher education to the third year of their teaching career?

\section{Methodology}

The data for the current study are drawn from four semi-structured telephone interviews implemented over four years (see Arnett, Mady, \& Muilenburg, 2014 for 
information on the broader five-year study of which this data is a part). The 20- to 45minute exchanges occurred in May and June of each year of the study, were conducted by a trained research assistant, and were recorded with permission and transcribed for analysis. Largely, the interviews from one year to the next followed the same protocol. Four questions in the interview protocol directly addressed the question of exclusions or exemptions from FSL study for the targeted learner populations: Two questions asked the participants to comment directly on the idea of exempting each of the respective student populations from FSL programs, ${ }^{4}$ while two questions asked about the suitability of FSL study for the respective student populations. ${ }^{5}$ The term suitability in the latter questions is known by many in the field to signal whether certain students should be excluded from FSL study. Thus, to some degree, the pairs of questions served to corroborate each other. In Year 4 of the study, the questions about suitability were replaced by questions about recommendations for transferring out of FSL.

Given the goals of the present paper, the authors manually isolated participants' responses to the targeted interview questions, organizing them in tables that documented the year-over-year response (per participant), and then, within each year, listing the responses across the participants. The responses were coded in a three-level colour scheme: green to indicate a favourable view of the students being included or remaining in the FSL program, yellow to indicate a mixed position (positive or negative view, but with qualifiers or conditions on the position), or red to indicate a position in favour of excluding or exempting the student from FSL study. Once these tables were constructed, general patterns were noted in their global views and the rationales for their positions. While it would have been possible to quantify the views according to this coding scheme, the nuance of their responses required a more qualitative treatment of the data for organizing the findings.

\section{Participants}

A group of 15 interview participants participated off and on over the four years of this study. From the group of 15 that formed part of the larger study, four participated consistently over the four years, when the interview protocol was largely the same. These are the four informants for this case study. Table 1 presents an overview of the participants, their Bachelor of Education (B.Ed.) backgrounds, and their teaching assignments.

All of the participants entered their teaching careers in the provinces where they completed their teacher education programs. Agnès was the only participant who was not from the province in which the program was completed. She was the only Francophone of the group and also had the most stable teaching assignment of all of the participants, remaining with the FI program for the entirety of the study. Ontarian Chantal completed her teaching practicum in core French, but spent the first two years of her teaching career

\footnotetext{
${ }^{4}$ When should ELLs be exempt from FSL study? When should students with learning difficulties be exempt from FSL study?

${ }^{5}$ Do you think French is a suitable program of study for ELLs? Do you think French is a suitable program of study for students with learning difficulties?
} 
in FI, before switching to the core French program in her third year of teaching (Year 4 of the study). Delphine's school assignment varied from year to year when she was in British Columbia, but she was consistent in her involvement in FI. Marie did have Francophone roots that were more openly shared in Year 3 of the study, but was initially positioned as an Anglophone. She too, was in a FI context both for her B.Ed. and for the initial years of her career.

\section{Table 1}

Year-by-Year Breakdown of Participants' Teaching Context

\begin{tabular}{|c|c|c|c|c|}
\hline $\begin{array}{l}\text { Participant (province of } \\
\text { B.Ed. program, } \\
\text { first language) }\end{array}$ & $\begin{array}{l}\text { Year } 1 \\
\text { (B.Ed. } \\
\text { year) }\end{array}$ & $\begin{array}{c}\text { Year } 2 \\
\text { (1st year of } \\
\text { teaching) }\end{array}$ & $\begin{array}{c}\text { Year } 3 \\
\text { (2nd year of } \\
\text { teaching) }\end{array}$ & $\begin{array}{l}\text { Year } 4 \\
\text { (3rd year of } \\
\text { teaching) }\end{array}$ \\
\hline Agnès (PEI, Francophone) & $\mathrm{FI}$ & FI Grade 3 & FI (grade unknown) & FI Grade 1 \\
\hline Chantal (ON, Anglophone) & $\mathrm{CF}$ & FI Grade 1 & FI Grade 1 & CF Grades 1-6 \\
\hline Delphine (BC, Anglophone) & $\mathrm{FI}$ & $\begin{array}{l}\text { FI, Grade 3, FI } \\
\text { Grade 7, LTO } \\
\text { contracts }\end{array}$ & $\begin{array}{l}\text { FI across various } \\
\text { Grades } 3-7, \text { LTO } \\
\text { contract }\end{array}$ & FI Grades 3/4 \\
\hline Marie (PEI, Anglophone) & $\mathrm{FI}$ & FI Grade 5 & FI Grade 5 & FI Grades 5/6 \\
\hline
\end{tabular}

Note: CF, core French; FI, French immersion; LTO, long term occasional

Thus, the majority of the case study participants were experienced with the FI program, and the core French experience was restricted to one practicum and one teaching assignment. This is noteworthy because of much of the dialogue in Canada about FSL study and its suitability for all student populations has been framed through discussion of FI, even though that program is not as commonly used for teaching French to children in Canada (Canadian Parents for French, 2012).

\section{Findings}

In this section we consider the four general areas of focus for this study by reviewing patterns in the comments shared by the participants: (a) exemptions for ELLs, (b) exemptions for students with learning difficulties, (c) suitability of FSL study for ELLs, and (d) suitability of FSL study for students with learning difficulties. We review the considerations of suitability for both learner populations simultaneously because of the patterns that emerged in those findings.

\section{Views on Exempting ELLs from FSL}

When looking at the responses as a collective, as the participants moved from their preparation and first year into the second and third years of their teaching, we observed a shift in their thinking about exemptions from FSL study for ELLs. This shift could be due to increased experience with teaching, though not necessarily with ELLs, as the participants reported working with just a few ELLs over the course of the study. The data revealed that participants had much more experience working with students with learning difficulties than with ELLs. 
In the first half of the study, the participants were less willing to consider exemptions for ELLs, but became more open to them in the second half of the study. Initially, exemption was viewed less favorably, either because of beliefs that the teacher needed to be prepared to help every student navigate the language learning experience or because of beliefs that the act of studying French and English as a newcomer was part of developing a Canadian identity. The only deviation was from Chantal, who was concerned from the outset about ELLs with learning difficulties and their pursuit of FSL study; and this theme showed up in her responses over the years. In response to the question of whether ELLs should be exempt from FSL, the following responses are representative of the views shared in the first two years of the study:

I don't think that they should unless there's maybe another learning issue other than the language, but I don't think the language itself is a reason to be exempted. (Chantal, Year 1)

No. I think there are adaptations that could be made. Adaptations could be made, it's not a matter of banning the student from learning, but probably has more to do with training the teacher. How to better adapt the material towards that student would be more of a concern. (Marie, Year 1)

They should not because I think Canada is a bilingual, so I think everyone should learn French and English in Canada. (Agnès, Year 2)

In Year 3 and Year 4, the stances on exemption started to change, as the participants expressed concern for ELLs navigating learning difficulties and/or their general progress in English. Thus, being an ELL, in and of itself, was not necessarily a problem for the participants; it was more of a question of the type of ELL - one who may also have a learning difficulty or was challenged meeting expectations in English. In either case, the participants seemed to converge around the idea of exemption being an appropriate response if the student had challenges with language learning - either in French or in English. The most representative quotations from this strand occurred in Year 4. For example, Agnès, in Year 4, felt that an ELL with a learning difficulty might be better matched to the English program:

Well, if they have like a serious learning disability and that the language is like a barrier to learn anything else...like because we do math in French and everything in French. Well in that case, if it's blocking them to learn something, that case I think it will be better for them if they go back in English.

As mentioned previously, Chantal was concerned about the intersection of learning difficulties with ELLs from the outset, but Year 4, her framing of difficulty was a seemingly broader and more focused on the idea of general challenges in learning English.

I think if they're struggling with the English language, if that's the language that's spoken around them, that they should switch to the English program. Especially since, if math is done in French and they're really struggling with the French language, that's another opportunity for them to practise their English if that's done in English as well. And then they can still have the, the half hour or the hour a day of French in the core program, but still have more practice with their English language in the other basic subjects. (Chantal, Year 4) 
Several of the rationales in Year 3 and Year 4 reflected an idea found in Chantal's response-that English development should not be compromised for the sake of continued study in French. In the two quotations that are shared here, it is also worth noting their shared concern for progress in math class because of challenges with the target language. As shown in Culligan (2010), language skills in French are a concern to teachers in relation to math study in immersion.

In a couple of the quotations that expressed concern about progress in English, the timing of an ELL's arrival into the system also figured into the rationale - in the sense that they would be joining French too late to be able to reach the same level of mastery as peers who had been studying the language longer. In Mady's (2015a) study in the FI context, however, ELLs' English test results were on par with their Canadian-born peers despite being immigrants to Canada and thus having had less exposure to English. As it pertains to time and its potential impact on French, research conducted in a core French context (Mady, 2007) found that ELLs could perform on level with their Canadian-born peers despite briefer FSL study. Through a comparison of multi-skills French proficiency test results, Mady revealed that ELLs, who had five years less of FSL study, outperformed the English-speaking Canadian-born group on one speaking test component and outperformed the multilingual Canadian-born group on another speaking test component, with no other significant differences found.

\section{Views on Exempting Students with Learning Difficulties from FSL}

Just as the participants experienced a noted shift from the first half of the study to the second half in their views about exempting ELLs from FSL, they also shifted in their positions about exempting students with learning difficulties from FSL.

During Year 1 and Year 2, the participants were mixed in their views. There was a general belief that exemptions might be necessary for this student group, but there was more reluctance to consider exemption. Delphine's response to the question in Year 2 provides a representative quotation of this situation. We note that she was teaching in the FI program, which has historically confronted questions about whether FSL study should continue for a student who has difficulties. Her statement also invokes one of the dilemmas that is often faced within the larger situation - the child's love for the program in spite of the challenges he or she has experienced. Delphine's reply seems to suggest that the absence of success is guiding the decision, not the fact that supports are not able to be offered, or that the student wants to leave; there is no sense, though, as to who defined success and its appearance:

As a last resort. I think even one of my little guys is going to leave the program next year and he doesn't want to leave and right now there is so many supports in place that there is no need to take him out just because he hasn't had a lot of success this year, in some subject areas. So definitely as a last resort. (Delphine, Year 2)

By Year 3, all of the participants were uniformly more open to the idea of exemption from FSL study, and there were three main themes within their responses-(a) concerns for the emotional well-being of the student, (b) concerns for the student's grade-level achievement in English, and (c) the extent of the supports that could be offered. However, it 
was often the student's emotional state that was the key force in their rationale, and that theme was nowhere in their responses for Year 1 and Year 2 of the study.

Yeah, I think along the same lines, if it's something they're just not able to handle and if it's going to make them have more difficulty and strife in their day by just being in French class, then yes. (Chantal, Year 3)

Well, it depends if he's able to reach the outcomes, even if there's adaptations, I think that that can be a good thing, but if it's too much of a challenge and the student experiences a lack of self-confidence and it becomes to be like a barrier or like a psychological barrier for the student, then I think it will be better for him to go be in the English program. (Agnès, Year 3)

If they really hate it, if they really, really struggle with it and they notice that that's making them miserable. (Marie, Year 3)

\section{Views on Suitability of FSL Study for ELLs and Students with Learning Difficulties}

As mentioned in the introduction to this section, the questions about suitability of FSL study for these learner populations were paired with questions about exemption as a way to test the general stability of the participants' views. Generally, the responses to questions about suitability supported the ideas that participants had previously shared about exemption; but some variation in the rationales introduced new themes or emphasized a particular line of thinking, as compared to responses about exemption. Because the responses for both learner populations had such similar trends, we have chosen to discuss them simultaneously.

All four of the participants regularly deemed FSL to be a suitable program for both ELLs and students with learning difficulties. Further, none of them ever cited the goals or structure of FSL, in general, as a reason to deem the program unsuitable for the students.

Regarding ELLs, participants consistently cited the belief that being multilingual was within reach of these students and, more particularly, that it was something they should have the chance to pursue through FSL study. Agnès's response from Year 3 and Chantal's response from Year 2 provide representative quotations for this theme:

Ah yes, they know other language that means they can, if they can learn English in Canada they can learn language. They know already another language, their minds are already used to different language. So yea. (Agnès, Year 3)

Yes. Definitely. I think that once you have already learned another language. And if they're already learning English I think that it is a lot easier to catch patterns and pick up an additional language. (Chantal, Year 2)

Marie's responses to this question also consistently invoked the idea of becoming multilingual. It is noteworthy, however that in Year 1, her emphasis on becoming multilingual was secondary to her concerns about learning needs and the social setting. At that time, she simultaneously invoked intellectual difficulties and a consideration of where the ELL had settled as reasons for which FSL study was not suitable for ELLs.

Like I said, in this area where it's definitely a minority language, you'd have to learn English first, then tackle the French, I don't see any reason barring, you know, severe 
intellectual deficiencies, why they shouldn't. It would just add to their communication abilities. (Marie, Year 1)

As of Year 2, Marie's response mirrored that of all of the other participants - that the primary reason for which FSL was suitable for ELLs was to add to their language repertoires.

Turning to students with learning difficulties, again, the participants' responses revealed a belief that the inherent structure and goals of FSL programming were not incompatible with the needs students with learning difficulties at a broad level; none of them were comfortable making a blanket statement that students with learning difficulties should not be a part of FSL programs. In fact, several of them emphasized that students with learning difficulties were entitled to a chance to succeed with French. Representative quotations from this theme are provided by Chantal and Marie.

Yes, because in my brief experience in French I have seen that students with learning difficulties can excel in that class. So, I see them as any other student, they have a chance to succeed, and if they don't understand it or they're having difficulties, we can still try to help them just like we would any student. (Chantal, Year 1)

I mean, I know kids who have LDs [learning disabilities], who have intellectual deficiencies who are learning French and they're doing fine, and in Canada that's wonderful, and I think if they have the right to learn it, they shouldn't be denied that right, I'm all about inclusion in immersion because right now it's such an elitist program and it always has been and it needs to change because the English are going to revolt because we get the best and they get the rest, and it's not supposed to be like that. (Marie, Year 3)

However, at one point or another, all of them also indicated that on a case-by-case basis, a student's individual learning needs may not be a match for the FSL program; in other words, the notion of suitability was one of individual consideration. A representative quotation from Delphine is offered:

Depending on what the learning disability is. So if it is about language acquisition and about, umm, if they're not having difficulties with that second language, then probably not. Yea, so it depends, if it is math, it was a math thing, disability, then I would say French is fine for them. So yea, it depends on what the difficulty is.

Occasionally, early in the study, the respondents also considered the methods of instruction within the FSL program in relation to the question of suitability. Both Marie and Delphine realized how teaching methods could influence the extent a learning environment supported a student with learning difficulties. As Delphine noted in her response to this question in Year 1, "It's not that they should be banned from French, it's a matter of how we're teaching it." By Year 3, though, the focus in all of the rationales was solely on the individual learning needs as a reason for questioning suitability.

\section{Discussion and Conclusion}

Through a case study of a small group of novice FSL teachers, mostly attached to the less common FI program, our research revealed some interesting trends in the beliefs of this newly prepared and inducted population. Participants were generally open to the idea 
of including students who are ELLs and/or have learning difficulties in FSL programs. However, participants viewed exemption as a reasonable path when, in isolated ways, the program was viewed as not being suitable for the student's needs.

For ELLs, typically, the rationale for these views centred on concerns about the student navigating too much language learning, experiencing minimal success, and/or having additional challenges such as learning difficulties. Some of these perceptions are contrary to research findings. Research (e.g., Mady, 2015a) has revealed ELLs to be capable of adding English and French to their language repertoires to the same or greater extent than their Canadian-born peers. Such results are supported by European research that has found bilingual students to be advantaged in learning additional languages (e.g., Peyer, Kaiser, \& Berthele, 2010; Tullock \& Fernández-Villanueve, 2013). Participants' perspective on ELLs may be grounded in a monolingual bias supported by the Englishdominant Canadian context in which language learning apart from English is viewed as a luxury rather than commonplace. Future research examining whether and, if so, how practical adaptations facilitate the inclusion of ELLs and their language development would prove beneficial and would potentially offer means by which teachers could adapt their instruction to better support ELLs. Concerns regarding ELLs with learning difficulties, however, is a question that needs significant consideration on the part of teachers, administrators, and the system more broadly. Given the research showing ELLs to be misdiagnosed with learning difficulties (e.g., Cummins, 1984; Mytkowicz, 2010), ELLs need to be given adequate time and support to acquire language (5-7 years) and, where such difficulties persist, must be given support from specialists in learning difficulties and in acquisition of English as a second language.

Regarding students with learning difficulties, it is noteworthy that the participants were committed to giving such students a chance to study FSL, but felt that there could be times when the FSL study should not continue. On the surface, such a stance is arguably inclusive, but it is worth noting that French is typically the only subject in which students are removed from a learning environment because of challenges: Other content areas typically are expected to continue to provide support, even when it is apparent the student's emotional response is negative (Arnett, 2013). FSL continues to be unique in that regard, and it is clear from the responses here that the concern for the affective dimensions are viewed as being an acceptable reason to remove a student from FSL study.

Our second research question asked to what extent participant beliefs were dynamic, so it is also interesting to note how, at least for the question about exemptions, this small sample experienced a noticeable shift in their views between their first and second year of teaching (Year 2 and Year 3 of the study). As another analysis of the data from the larger study revealed, dynamism in beliefs is often a result of experiences through everyday events in the classroom (Arnett et al., 2014). However, for this particular group of participants, their experience with ELLs remained very minimal; none of them ever taught more than two ELLs in the entirety of the study. In contrast, all of them had experience with students with learning difficulties, which could explain why the rationales offered about exemption and suitability for ELLs often alluded to learning difficulties as well. It could prove advantageous for a future longitudinal study to provide professional development sessions to teachers over time and to examine the influence of such sessions, if any, on teachers' beliefs and practices. 
Given the scale of this study, generalizations are not possible. Another limitation was a lack of detail in some interviews: As the analysis continued, there were certainly moments when it was lamented that the research assistants had not probed certain comments or explanations further. Nevertheless, this study offers a small chronicle of how beliefs about a key construct within modern Canadian FSL education (exemption/suitability) were rationalized and how they changed over time. In doing so, it provides a starting point for additional conversations, which are needed within the field as expectations continue to be raised for more inclusive FSL programming.

\section{References}

Alberta Education. (2013). Resources to support students with diverse learning needs for francophone and French immersion schools. Edmonton, AB: Author.

Arnett, K. (2003). Teacher adaptations in core French: A case study of one Grade 9 class. The Canadian Modern Language Review, 60(2), 173-198.

Arnett, K. (2010). Scaffolding in a Grade 8 core French classroom: An exploratory case study. The Canadian Modern Language Review, 66(4), 557-582.

Arnett, K. (2013). The genesis and perpetuation of exemptions and transfers from French second language programs for students with diverse learning needs: A preliminary examination and their link to inclusion. In C. Mady (Ed.), Minority populations in Canadian second language education (pp. 103-117). Toronto, ON: Multilingual Matters.

Arnett, K., Mady, C., \& Muilenburg, L. (2014). Canadian FSL teacher candidate beliefs about students with learning difficulties. Theory and Practice in Language Studies, 4(3), 447-457.

Bourgoin, R. (2014). The predictive effects of L1 and L2 early literacy indicators on reading in French immersion. Canadian Modern Language Review, 70(3), 355-380. doi:10.3138/cmlr.2346

Bourgoin, R. (2016). French immersion "So why would you do something like that to a child?": Issues of advocacy, accessibility, and inclusion. International Journal of Bias, Identities and Diversities in Education, 1(1), 42-58.

Bruck, M. (1978). The suitability of early French immersion for the language disabled child. The Canadian Modern Language Review, 34(5), 884-887.

Bruck, M. (1982). Language disabled children: Performance in an additive bilingual education program. Applied Psycholinguistics, 3, 45-60.

Canadian Parents for French. (2012). The proceedings of the Canadian Parents for French roundtable on academically challenged students in French-second-language programs. Ottawa, ON: Author.

Culligan, K. (2010). Pente or slope? Using student voices to explore program choice and experiences in secondary French immersion mathematics. The Canadian Modern Language Review, $66(3), 421-444$.

Cummins, J. (1984). Bilingualism and special education: Issues in assessment and pedagogy. Clevedon, UK: Multilingual Matters.

Dagenais, D., \& Berron, C. (2001). Promoting multilingualism through French immersion and language maintenance in three immigrant families. Language, Culture and Curriculum, 14(2), 142-155.

Dagenais, D., \& Jaquet, M. (2000). Valorisation du multilinguisme et de l'education bilingue dans des familles immigrantes. Journal of International Migration and Integration, 1(4), 389-404. 
Dagenais, D., \& Moore, D. (2008). Représentations des littératies plurilingues, de l'immersion en français et des dynamiques identitaires chez des parents en chinois. Revue Canadienne des Langues Vivantes, 65(1), 11-31.

Delaney, J. G. (2002). Educational policy studies: A practical approach. Calgary, AB: Detselig Enterprises.

Genesee, F. (2007). French immersion and at-risk students: A review of research evidence. The Canadian Modern Language Review, 63(5), 655-688.

Genesee, F. (2008). Is immersion right for students with academic challenges? In The state of French-second language education in Canada 2008 (pp. 12-13). Ottawa, ON: Canadian Parents for French.

Genesee, F. (2012). The suitability of French immersion for all learners: What does the research say. In The state of second language education in Canada 2012: Executive summary (pp. 5-6). Ottawa, ON: Canadian Parents for French.

Lambert, W. E., \& Tucker, G. R. (1972). Bilingual education of children: The St. Lambert experiment. Rowley, MA: Newbury House Publishers.

Le Bouthillier, J. (2013). The writing processes of a Grade 7 French immersion student with Asperger syndrome. In K. Arnett \& C. Mady (Eds.), Minority populations in second language education: Broadening the lens from Canada. Bristol, UK: Multilingual Matters.

Mady, C. (2007). The suitability of core French for recently arrived adolescent immigrants to Canada. Canadian Journal of Applied Linguistics, 10(2), 177-196.

Mady, C. (2010). Motivation to study core French: Comparing recent immigrants and Canadian-born secondary school students. Canadian Journal of Education, 33(3), 564-587.

Mady, C. (2012a). Official language bilingualism to the exclusion of multilingualism: Immigrant student perspectives on French as a second official language in "English-dominant" Canada. Language and Intercultural Communication, 12(1), 74-89.

Mady, C. (2012b). Voices of immigrant adults: Perspectives and experiences with French as a second official language in "English-dominant" Canada. Intercultural Promenades: Journal of Modern Languages and Intercultural Studies, 1(1), 35-51.

Mady, C. (2013a). Immigrant status as an influential factor in additional language learning: A comparison of French language achievement of Canadian-born monolinguals, bilinguals and bilingual immigrants. Journal of Language Teaching and Research, 5(1), 12-20.

Mady, C. (2013b). Learning French as a second official language in Canada: Comparing monolingual and bilingual students at Grade 6. International Journal of Bilingual Education and Bilingualism, 17(3), 330-344. http://dx.doi.org/10.1080/13670050.2013.767778

Mady, C. (2015a). Can success lead to increased access?: Examining immigrants' English and French achievement in French immersion. Journal of Immersion and Content-Based Language Education, 3(2), 268-284.

Mady, C. (2015b). The bilingual advantage for immigrant students in FI in Canada: Linking advantages to contextual variables. International Journal of Bilingual Education and Bilingualism. doi:10.1080/13670050.2015.1041875

Mady, C. (2016). French immersion for English language learners?: Kindergarten teachers' perspectives. Alberta Journal of Educational Research, 62(3), 253-267.

Mady, C., \& Black, G. (2012). Access to French as a second official language programs in Englishdominant Canada. Alberta Journal of Educational Research, 57(4), 498-501. 
Mytkowicz, C. (2010). Multilingual college students with learning disabilities. In M. Ficksman \& J. Adelizzi (Eds.), The clinical practice of educational therapy (pp. 113-129). New York, NY: Routledge.

Ontario Ministry of Education. (2015). Including students with special education needs in French as a second language programs. Toronto, ON: Author.

Peel District School Board. (n.d.). Is French immersion right for my child? [Video file]. Retrieved from http://peelschools.org/parents/programs/french/Pages/default.aspx

Peyer, E., Kaiser, I., \& Berthele, R. (2010). The multilingual reader: Advantages in understanding and decoding German sentence structure when reading German as an L3. International Journal of Multilingualism, 7(3), 225-239. doi:10.1080/14790711003599443

Province of British Columbia. (2004). The language education policy. Victoria, BC: Author. Retrieved from https://www2.gov.bc.ca/gov/content/education-training/administration/legislation-policy

Trites, R. L., \& Price, M. A. (1976). Learning disabilities found in association with French immersion programming. Ottawa, ON: University of Ottawa Press.

Trites, R. L., \& Price, M. A. (1977). Learning disabilities found in association with French immersion programming: A cross-validation. Ottawa, ON: University of Ottawa Press.

Tullock, B., \& Fernandez-Villanueva, M. (2013). The role of previously learned languages in the thought processes of multilingual writers at the Deutsche Schule Barcelona. Research in the Teaching of English, 47(4), 420-441.

\section{Authors' Note}

Correspondence concerning this article should be addressed to Katy Arnett, Department of Educational Studies, St. Mary's College of Maryland, 47645 College Drive, St. Mary's City, MD 20686. Email: kearnett@smcm.edu 